\title{
Kwaliteit van leven bij rokers: zijn functionele beperkingen belangrijker dan longfunctie?
}

Roeland Geijer, Alfred Sachs, Theo Verheij, Huib Kerstiens, Marijke Kuyvenhoven, Arno Hoes

\section{Inleiding}

In vrijwel alle richtlijnen is de graad van chronisch obstructief longlijden (COPD) alleen gebaseerd op de mate van luchtwegobstructie, dat wil zeggen het geforceerde expiratoire volume in één seconde $\left(\mathrm{FEV}_{1}\right)$, zonder rekening te houden met andere aspecten, zoals de ernst van de luchtwegklachten.1,2 Opmerkelijk is dat de gezondheidsgerelateerde kwaliteit van leven, dat wil zeggen individuele tevredenheid of geluk voor zover die afhankelijk is van de gezondheid, nauwelijks verband houdt met de ernst van de luchtwegobstructie. ${ }^{3-8}$ Belangrijker in dit opzicht is de functionele status, dat wil zeggen het individuele vermogen om normale dagelijkse activiteiten uit te voeren in de verschillende domeinen van het leven. ${ }^{3}$ Dyspneu heeft bij patiënten met COPD het grootste negatieve effect op deze functionele status: de score op een dyspneuschaal lijkt sterker te correleren met de kwaliteit van leven dan de longfunctie. ${ }^{9}$ Bekend is ook dat patiënten de huisarts consulteren vanwege toenemende luchtwegklachten en

\section{Samenvatting}

Geijer RMM, Sachs APE, Verheij TJM, Kerstjens HAM, Kuyvenhoven MM, Hoes AW. Kwaliteit van leven bij rokers: zijn functionele beperkingen belangrijker dan longfunctie? Huisarts Wet 2009;52(1):39-44.

Achtergrond De internationaal gebruikelijke indeling van het Global Initiative for Chronic Obstructive Lung Disease (GOLD) voor chronisch obstructief longlijden (COPD) is alleen gebaseerd op het geforceerde expiratoire volume in één seconde $\left(\mathrm{FEV}_{1}\right)$ en houdt geen rekening met het lichamelijk functioneren.

Doel Wij wilden achterhalen in hoeverre de kwaliteit van leven van COPD-patiënten verband houdt met beperkingen in het lichamelijk functioneren zoals gemeten met de dyspneuschaal van de Medical Research Council (MRC), en met de mate van luchtwegobstructie.

Methode De deelnemers aan het onderzoek waren 395 mannelijke rokers van 40 tot 65 jaar (gemiddelde leeftijd 55,4 jaar, rookhistorie gemiddeld 27,1 pakjaren), zonder eerdere diagnose van COPD en ingeschreven in een huisartsenpraktijk in IJsselstein. $\mathrm{Zij}$ ondergingen een spirometrietest en vulden een algemene (SF-36) en een ziektespecifieke (QOL-RIQ) vragenlijst in over de kwaliteit van leven.

Resultaat Bij 99 deelnemers $(25,1 \%)$ vonden wij functiebeperkingen en bij 159 deelnemers (40,2\%) maten wij een luchtwegobstructie. De beperking in lichamelijk functioneren correleerde sterker met alle kwaliteit-van-levensubschalen dan de ernst van niet zozeer vanwege een afnemende longfunctie. Er is dan ook kritiek gerezen op de criteria van het Global Initiative for Chronic Obstructive Lung Disease (GOLD), die eenzijdig gebaseerd zijn op de longfunctie. ${ }^{7}$

In de dagelijkse behandeling van rokers, al dan niet met een vroeg stadium van COPD, is er behoefte aan een eenvoudig en gestandaardiseerd instrument om de gezondheidsgerelateerde kwaliteit van leven vast te stellen - bijvoorbeeld voorafgaand aan een gerichte stoppen-met-rokeninterventie. De dyspneuschaal van de Medical Research Council (MRC) zou een dergelijk instrument kunnen zijn, omdat deze de mogelijkheid biedt patiënten met ernstig COPD te categoriseren op basis van hun lichamelijk functioneren. ${ }^{6}$ Nog niet bekend was echter in hoeverre de MRCdyspneuschaal enerzijds en de ernst van de luchtwegobstructie anderzijds samenhangen met de kwaliteit van leven van rokers die een verhoogde kans op of een vroeg stadium van COPD hebben. Het doel van ons onderzoek was deze verbanden te bestuderen.

de luchtwegobstructie. Ook in de multivariate analyse bleef dit verband sterker.

Conclusie Bij rokers van middelbare leeftijd geeft de MRC-schaal een betere indruk van de kwaliteit van leven dan de GOLD-stadiering. Toekomstige indelingen van COPD dienen meer rekening te houden met beperkingen van het lichamelijk functioneren door dyspneu en niet alleen uit te gaan van het $\mathrm{FEV}_{1}$.

Universitair Medisch Centrum Utrecht, Julius Centrum voor Gezondheidswetenschappen en Eerstelijnsgeneeskunde, Postbus 85500, 3508 GA Utrecht: dr. R.M.M. Geijer, huisarts; dr. A.P.E. Sachs, huisarts; prof.dr. Th.J.M. Verheij, hoogleraar Huisartsgeneeskunde; dr. M.M. Kuyvenhoven, medisch socioloog; prof.dr. A.W. Hoes, hoogleraar Klinische epidemiologie.

Universitair Medisch Centrum Groningen, afdeling Inwendige geneeskunde-longziekten: prof.dr. H.A.M. Kerstjens, hoogleraar Longziekten, in het bijzonder chronisch obstructief longlijden.

Correspondentie: rmmgeyer@hotmail.com

Mogelijke belangenverstrengeling: niets aangegeven. Het onderzoek werd gefinancierd door het Nederlands Astmafonds (referentienummer 3.4.01.93)

Dit onderzoek is eerder verschenen als: Geijer RM, Sachs AP, Verheij Th, Kerstjens HA, Kuyvenhoven MM, Hoes AW. Quality of life in smokers: focus on functional limitations rather than on lung function? Br J Gen Pract 2007;57:477-82. Publicatie gebeurt met toestemming van de uitgever. 


\section{Methode}

In 1998 namen 702 rokende mannen, 40 tot 65 jaar oud en ingeschreven bij een huisartsenpraktijk in IJsselstein, deel aan een screeningsonderzoek dat tot doel had niet eerder bekende luchtwegobstructie vast te stellen. De screening omvatte alleen mannen omdat bij hen de prevalentie van COPD hoger is en omdat de financiële middelen beperkt waren. ${ }^{10}$ In 2003 nodigden wij 601 (86\%) van de oorspronkelijke deelnemers uit voor een followuponderzoek. Het merendeel van de overige deelnemers kon niet meer benaderd worden doordat een van de huisartsenpraktijken niet meer in het onderzoek participeerde. Uiteindelijk namen 436 van de 601 aangeschreven personen (73\%) deel aan het vervolgonderzoek. Het onderzoek werd goedgekeurd door de medischethische commissie van het UMC Utrecht.

\section{Longfunctieonderzoek}

Wij onderzochten de longfunctie van de deelnemers met een Jaeger ${ }^{\circledR}$ spirometer. Details van de procedure zijn elders besproken. ${ }^{10}$ Kort samengevat moest elke deelnemer in zittende houding ten minste driemaal een acceptabele geforceerde vitale capaciteit (FVC) blazen. Deelnemers met een $\mathrm{FEV}_{1}$ lager dan 85\% van de voorspelde waarde kregen 4 puffs salbutamol $100 \mu \mathrm{g}$ via een inhalatiekamer en herhaalden de test na 15 minuten. Deelnemers van 60 jaar en ouder kregen 2 puffs ipratropium $20 \mu \mathrm{g}$ en herhaalden de test na 30 minuten. Ervaren en speciaal getrainde longfunctieassistenten in dienst van een eerstelijns diagnostisch centrum verrichtten alle longfunctiemetingen. De spirometer werd dagelijks voor het begin van de serie metingen gekalibreerd met een éénliterspuit. De eerste en de tweede auteur beoordeelden onafhankelijk van elkaar de kwaliteit van de flowvolumecurves en de tijdvolumecurves aan de hand van de criteria van de American Thoracic Society. ${ }^{11}$ De voorspelde waarden van de FVC en FEV werden berekend met behulp van de regressievergelijkingen van de Europese Gemeenschap voor Kolen en Staal (EGKS). ${ }^{12}$

De internationale GOLD-richtlijn definieert COPD als een postbronchodilatatoire $\mathrm{FEV}_{\mathrm{l}} / \mathrm{FVC}$-ratio $<0,7$ en onderscheidt vier ernststadia aan de hand van de postbronchodilatatoire $\mathrm{FEV}_{1^{-}}$ waarden: ${ }^{1,2}$

- GOLD-stadium I = licht COPD: $\mathrm{FEV}_{1} \geq 80 \%$ van voorspeld.

- GOLD-stadium II = matig ernstig COPD: FEV 1 50-80\% van voorspeld.

- GOLD-stadium III = ernstig COPD: FEV 1 30-50\% van voorspeld.

- GOLD-stadium IV = zeer ernstig COPD: $\mathrm{FEV}_{1}<30 \%$ van voorspeld (of $<50 \%$ bij verschijnselen van chronisch longfalen).

Voorafgaand aan elke longfunctietest maten wij lengte en gewicht van de deelnemers en berekenden wij de body mass index (kg/ $\mathrm{m}^{2}$ ). Het aantal pakjaren berekenden wij door het aantal sigaretten per dag te delen door twintig en te vermenigvuldigen met het aantal jaren dat de deelnemer gerookt had.

\section{Wat is bekend?}

- Bij patiënten met matig ernstig en ernstig COPD is de kwaliteit van leven sterker geassocieerd met dyspneu dan met de ernst van de luchtwegobstructie. Bij patiënten met licht COPD is hierover echter weinig bekend.

Wat is nieuw?

- Ook bij patiënten met een verhoogde kans op COPD of met licht COPD zijn beperkingen door dyspneu een betere indicator voor de kwaliteit van leven dan de longfunctie $\left(\mathrm{FEV}_{1}\right)$.

\section{Functionele beperkingen}

Wij legden de functionele beperkingen vast met behulp van een Nederlandse vertaling van de MRC-dyspneuschaal. ${ }^{13}$ Deze vijfpuntsschaal (zie tabel 1) is al jaren in gebruik en kan eenvoudig worden toegepast. ${ }^{14}$ Wij vroegen de deelnemers daarnaast of zij last hadden van chronisch hoesten, dat wil zeggen 'bijna elke dag hoesten gedurende de voorafgaande drie maanden'.

\section{Comorbiditeit}

Als comorbiditeit definieerden wij cardiovasculaire aandoeningen, aandoeningen van het bewegingsapparaat, een nierziekte, kanker of diabetes mellitus, zoals vastgelegd in het medisch dossier van de huisarts. Een aandoening was aanwezig als wij de diagnose van huisarts of specialist aantroffen in het dossier of in de medische correspondentie.

\section{Kwaliteit van leven}

Wij gingen de algemene kwaliteit van leven na met behulp van de Short Form Health Survey questionnaire (SF-36), en de ziektespecifieke kwaliteit van leven met de Quality Of Life in Respiratory Illness Questionnaire (OOL-RIQ). ${ }^{15,16}$ Beide vragenlijsten werden door de deelnemers zelf thuis ingevuld in de vier weken voorafgaand aan het longfunctieonderzoek. De SF-36 is een veelgebruikte, gevalideerde vragenlijst ${ }^{15,17,18}$ met 36 vragen, ingedeeld in acht subschalen: 'lichamelijk functioneren', 'rolbeperking door lichamelijk functioneren', 'lichamelijke pijn', 'algemene gezondheid', 'vitaliteit', 'sociaal functioneren', 'rolbeperking door emotionele problemen' en 'psychische gezondheid'. De scores worden lineair uitgezet op een schaal van nul tot honderd, waarbij een hogere score duidt op een betere kwaliteit van leven.

De QOL-RIQ is ontwikkeld en gevalideerd bij patiënten met licht tot matig ernstig astma of COPD die primair behandeld worden in de eerste lijn. De lijst bestaat uit 55 vragen die tot een totale score leiden, verdeeld over zeven subschalen ('ademhalingsproblemen', 'lichamelijke problemen', 'emoties', 'algemene bezigheden', 'situaties die ademhalingsproblemen uitlokken of verergeren', 'dagelijkse en huiselijke bezigheden' en 'sociale activiteiten, relaties en seksualiteit') waarop de respondenten kunnen aangeven in hoeverre zij hinder ondervinden van hun luchtwegklachten. De respondenten kunnen alle antwoorden aangeven op een zevenpunts likertschaal, variërend van 1 (helemaal geen hinder) tot 7 (ernstige hinder). Per subschaal mag maximaal de helft van 


\begin{tabular}{|c|c|c|}
\hline Gradatie & Omschrijving & Waarde* \\
\hline- & ik heb geen last van kortademigheid & 0 \\
\hline MRCI & ik word alleen kortademig bij zware inspanning & 1 \\
\hline MRC II & ik word alleen kortademig als ik me moet haasten op vlak terrein of als ik tegen een lichte helling oploop & \\
\hline MRC III & $\begin{array}{l}\text { door mijn kortademigheid loop ik op vlak terrein langzamer dan andere mensen van mijn leeftijd, of moet ik } \\
\text { stoppen om op adem te komen als ik in mijn eigen tempo loop }\end{array}$ & 2 \\
\hline MRC IV & $\begin{array}{l}\text { na ongeveer honderd meter lopen op vlak terrein of na een paar minuten lopen op vlak terrein moet ik stoppen } \\
\text { in verband met kortademigheid }\end{array}$ & \\
\hline MRC V & ik ben te kortademig om het huis uit te gaan, of ik ben kortademig tijdens het aan- of uitkleden & \\
\hline \multicolumn{3}{|c|}{ Luchtwegobstructie } \\
\hline- & geen luchtwegobstructie & 0 \\
\hline GOLD I & lichte luchtwegobstructie & 1 \\
\hline GOLD II & matig ernstige luchtwegobstructie & 2 \\
\hline
\end{tabular}

de items ontbreken en bij het berekenen van de totaalscore mag ten hoogste één subschaal ontbreken.

Wij berekenden de totaalscore van de QOL-RIQ en de subschaalscores van beide vragenlijsten door de itemscores op te tellen en de som te delen door het aantal valide items. Om de scores van de QOL-RIO makkelijker te kunnen vergelijken met die van de SF-36, transformeerden wij ze zodanig dat een hogere score duidde op een hogere kwaliteit van leven.

\section{Statistische analyse}

Wij berekenden spearmancorrelatiecoëfficiënten $\left(r_{s}\right)$ voor de samenhang tussen de MRC-dyspneuschaal en de GOLD-stadia enerzijds (onafhankelijke variabele) en de subschalen van de vragenlijsten anderzijds (afhankelijke variabele). Wij gaven de MRCscores het rangnummer 0 (geen hinder van kortademigheid), 1 (MRC-stadium I-II) of 2 (MRC-stadium III-V), en ook de GOLDstadia kregen rangnummer 0 (geen luchtwegobstructie), 1 (GOLDstadium I) of 2 (GOLD-stadium II) (zie tabel 1). Er waren geen deelnemers met GOLD-stadium III of IV.

De subschaalscores van SF-36 en QOL-RIQ bleken scheef verdeeld naar rechts, wat erop duidt dat een aanzienlijk deel van de deelnemers een maximumscore had ingevuld. De scores konden met geen enkele vorm van transformatie genormaliseerd worden. Daarom splitsten wij ze rond een afkappunt. Als afkappunten kozen wij de maximumscore minus het minimale betekenisvolle verschil $(100-5=95$ punten voor de SF-36, $7-0,5=6,5$ punten voor de QOL-RIQ). ${ }^{19,20}$ Scores van 96-100 op de SF-36 kregen aldus de waarde 0 , scores $\leq 95$ de waarde 1 , op de QOL-RIO kregen scores 6,5-7 de waarde 0 , en scores $\leq 6,5$ de waarde 1 . Met logistische regressieanalyse gingen wij vervolgens de associatie na van de MRC- en GOLD-scores enerzijds en de gedichotomiseerde scores op de beide kwaliteit-van-levenschalen anderzijds. Wij voerden de regressievergelijkingen uit met elke afzonderlijke kwaliteit-van-levensubschaalscore als uitkomstmaat.

\section{Resultaat}

In totaal verkregen wij van 395 mannelijke rokers (91\% van 436 deelnemers) een adequate spirometrietest en ingevulde vragenlijsten. Bij 27 deelnemers (6\%) was de spirometrietest niet adequaat en bij 14 deelnemers (3\%) waren een of meer vragenlijsten incompleet. De gemiddelde leeftijd was 55,4 jaar (SD 6,3) en de gemiddelde rookgeschiedenis 27,1 pakjaren (SD 19,3) (tabel 2). Bij 99 deelnemers (25, 1\% van 395 deelnemers) was er sprake van enige beperking in het lichamelijk functioneren door dyspneu (MRC-score I-V), en bij 159 deelnemers $(40,2 \%)$ was er sprake van COPD (tabel 2).

Waar de dyspneuscore matig correleerde $\left(\mathrm{r}_{\mathrm{s}} 0,52\right)$ met de totaalscore op de QOL-RIQ, correleerde de luchtwegobstructie slechts zwak met deze score $\left(\mathrm{r}_{\mathrm{s}} 0,22\right)$ (gegevens niet beschreven). De dyspneuscore had een (zwakke tot matige) correlatie met alle subschaalscores van beide vragenlijsten $\left(r_{s} 0,19-0,58\right)$, de ernst van de luchtwegobstructie had alleen een (zwakke) correlatie met de subschaalscores van de QOL-RIO $\left(r_{s}, 0,12-0,28\right)$ en enkele subschaalscores van de SF-36 ( $\left.r_{s} 0,13-0,20\right)$. De sterkste associaties traden op tussen de dyspneuscore en die subschalen die verband hielden met beperkingen in dagelijkse bezigheden, zoals de SF36-subschaal 'lichamelijk functioneren' $\left(r_{s} 0,53\right)$ en de QOL-RIQsubschaal 'dagelijkse en huiselijke bezigheden' ( $\left.r_{s} 58\right)$.

De dyspneu hing nauwer samen met alle kwaliteit-van-levensubschalen dan de ernst van de luchtwegobstructie, zoals tabel 3 laat zien. Nemen we bijvoorbeeld de oddsratio (OR) van een slechtere score op 'lichamelijk functioneren' uit de SF-36, dan was deze voor deelnemers met matig ernstige tot ernstige beperkingen op de dyspneuschaal ongeveer achtmaal zo hoog als voor deelnemers met lichte beperkingen (OR 8,4; 95\%-BI 4,6 tot 15,5). Dezelfde OR was voor deelnemers met matig ernstig COPD slechts licht verhoogd ten opzichte van deelnemers met licht COPD (OR 1,3; 95\%-BI 1,0 tot 1,5). De OR's van de bivariate analyse kwamen nagenoeg overeen met die van de univariate analyse (gegevens niet beschreven).

\section{Discussie}

In ons cohort mannelijke rokers van middelbare leeftijd, van wie $40 \%$ met licht of matig ernstig COPD (GOLD I of II), hing de kwaliteit van leven nauwer samen met functionele beperkingen zoals gemeten met de MRC-dyspneuschaal dan met de ernst van de luchtwegobstructie, afgemeten aan het GOLD-stadium. Voor zover ons bekend is, is ons onderzoek het eerste dat dit verband aantoont in een algemene populatie van rokers met een verhoogde kans op of een vroeg stadium van COPD. 
Tabel 2 Kenmerken en kwaliteit van leven van 395 mannelijke rokers van middelbare leeftijd

\begin{tabular}{|c|c|c|}
\hline Kenmerken & $\begin{array}{c}\text { Gemiddelde, c.q. } \\
\text { percentage }\end{array}$ & SD \\
\hline Leeftijd (jaren) & $55,4^{\circ}$ & 6,3 \\
\hline Roken (pakjaren) & 27,1 & 19,3 \\
\hline Werkloos/gepensioneerd & $29 \%$ & - \\
\hline Alleenwonend & $9 \%$ & - \\
\hline Comorbiditeit* & $27 \%$ & - \\
\hline Chronisch hoesten & $23 \%$ & - \\
\hline BMI & 26,6 & 3,8 \\
\hline $\mathrm{FEV}_{1}(\mathrm{~L})$ & 3,5 & 0,7 \\
\hline $\mathrm{FEV}_{1} \%$ voorspeld & 98 & 16 \\
\hline Longfunctie & & - \\
\hline geen luchtwegobstructie & $59,7 \%$ & \\
\hline licht COPD (GOLD I) & $29,6 \%$ & - \\
\hline matig ernstig COPD (GOLD II) & $10,6 \%$ & - \\
\hline \multicolumn{3}{|l|}{ Functionele beperkingen door dyspneu } \\
\hline geen & $74,9 \%$ & \\
\hline licht (MRC I-II) & $17,7 \%$ & - \\
\hline matig ernstig of ernstig (MRC III-V) & $7,3 \%$ & - \\
\hline \multicolumn{3}{|l|}{ Algemene kwaliteit van leven ${ }^{\dagger}$} \\
\hline lichamelijk functioneren & 86,3 & \\
\hline rolbeperking in lichamelijk functioneren & 85,9 & 29,5 \\
\hline lichamelijke pijn & 83,3 & 22,5 \\
\hline algemene gezondheid & 66,1 & 18,8 \\
\hline vitaliteit & 68,3 & 19,2 \\
\hline sociaal functioneren & 87,9 & 18,4 \\
\hline rolbeperking in emotioneel functioneren & 88,9 & 26,9 \\
\hline psychische gezondheid & 78,4 & 16,4 \\
\hline \\
\hline $\begin{array}{l}\text { Ziektespecifieke kwaliteit van levent } \\
\text { totale score }\end{array}$ & & \\
\hline ademhalingsproblemen & 6,1 & 0,8 \\
\hline lichamelijke problemen & 6,4 & 0,7 \\
\hline emoties & 6,5 & 0,7 \\
\hline algemene bezigheden & 6,6 & 0,8 \\
\hline situaties die ademhalingsproblemen uitlokken of verergeren & 6,7 & 0,6 \\
\hline dagelijkse en huiselijke bezigheden & 6,5 & 0,6 \\
\hline sociale bezigheden, relaties, seksualiteit & 6,8 & 0,5 \\
\hline
\end{tabular}

COPD. ${ }^{8,19,22}$ De Nederlandse versie van de lijst bleek eveneens een betrouwbaar en valide instrument bij onderzoek in populaties met een chronische aandoening in Nederland. ${ }^{15}$ De scores op de SF-36-subschalen in ons onderzoek waren in hoge mate vergelijkbaar met de scores ontleend aan twee steekproeven uit de Nederlandse bevolking, hetgeen de bevinding ondersteunt dat een vroeg stadium van COPD de kwaliteit van leven niet ernstig beperkt. ${ }^{15}$ De betrouwbaarheid en validiteit van de QOL-RIQ is onderzocht bij patiënten in de eerste lijn met stabiel astma of COPD. ${ }^{16,22}$

Voor het meten van de beperkingen in lichamelijk functioneren gaven wij aan de MRC-dyspneuschaal de voorkeur boven andere klinische dyspneuschalen, zoals de Baseline Dyspnoea Index (BDI), de dyspneusubschalen van de St. George's Respiratory Questionnaire (SGRQ) en de Chronic Respiratory Disease Questionnaire (CRQ), omdat de MRC-dyspneuschaal een veelgebruikt en valide instrument is. $^{23}$

De meeste rokers zonder eerdere diagnose COPD hebben een lichte vorm van de aandoening. Onze resultaten zijn daarom niet zonder meer van toepassing op patiënten met ernstig COPD. Daartegenover staat ten eerste dat ook bij patiënten met ernstig COPD de ernst van de dyspneu aantoonbaar sterker gerelateerd is aan kwaliteit van leven dan de $\mathrm{FEV}_{1}{ }^{8,9,20,21}$ Ten tweede bestond ons cohort alleen uit mannelijke rokers. De meeste onderzoeken rapporteren bij vrouwen met COPD een lagere kwaliteit Wij maten de kwaliteit van leven met een algemene vragenlijst (SF-36) en een ziektespecifieke vragenlijst (QOL-RIQ). De SF-36 is betrouwbaar, gevoelig en valide gebleken bij patiënten met van leven dan bij mannen met COPD. 4,5,17,24 Vrouwen - rooksters én niet-rooksters - melden vaker luchtwegsymptomen dan mannen, en consulteren vaker de huisarts voor luchtwegklachten. ${ }^{25-29}$

Tabel 3 Bivariate associatie van beperkingen door dyspneu en luchtwegobstructie met kwaliteit van leven bij mannelijke rokers van middelbare leeftijd

\begin{tabular}{|c|c|c|c|c|}
\hline \multirow[t]{2}{*}{ Kwaliteit-van-levensubschalen } & \multicolumn{2}{|c|}{$\begin{array}{l}\text { Beperkingen door dyspneu } \\
\text { (MRC-score) }\end{array}$} & \multicolumn{2}{|c|}{$\begin{array}{l}\text { Ernst van de luchtwegobstructie } \\
\text { (GOLD-stadium) }\end{array}$} \\
\hline & $\mathrm{OR}^{*}$ & $95 \%-\mathrm{BI}$ & $\mathrm{OR}^{*}$ & $95 \%-\mathrm{BI}$ \\
\hline \multicolumn{5}{|l|}{ Algemene vragenlijst (SF-36) } \\
\hline lichamelijk functioneren & 8,4 & $4,6-15,5$ & 1,3 & $1,0-1,5$ \\
\hline - rolbeperking in lichamelijk functioneren & 2,9 & $2,0-4,3$ & 0,8 & $0,7-1,1$ \\
\hline - lichamelijke pijn & 1,7 & $1,2-2,5$ & 1,0 & $0,8-1,1$ \\
\hline - algemene gezondheid & 7,0 & $1,0-47,5$ & 1,0 & $0,7-1,4$ \\
\hline - vitaliteit & 8,3 & $1,2-55,8$ & 1,0 & $0,7-1,4$ \\
\hline . sociaal functioneren & 2,1 & $1,5-3,0$ & 1,0 & $0,8-1,2$ \\
\hline - rolbeperking in emotioneel functioneren & 2,5 & $1,7-3,7$ & 0,8 & $0,6-1,0$ \\
\hline - psychische gezondheid & 2,6 & $1,5-4,7$ & 1,1 & $0,9-1,4$ \\
\hline \multicolumn{5}{|l|}{ Ziektespecifieke vragenlijst (QOL-RIQ) } \\
\hline - totale score & 6,0 & $3,8-9,4$ & 1,3 & $1,0-1,6$ \\
\hline - ademhalingsproblemen & 3,7 & $2,2-6,3$ & 1,5 & $1,2-1,8$ \\
\hline - lichamelijke problemen & 4,5 & $2,9-7,0$ & 1,0 & $0,8-1,2$ \\
\hline - emoties & 4,7 & $3,1-7,1$ & 1,1 & $0,9-1,3$ \\
\hline - algemene bezigheden & 3,2 & $2,2-4,7$ & 1,0 & $0,9-1,3$ \\
\hline $\begin{array}{l}\text { situaties die ademhalingsproblemen uitlokken of } \\
\text { verergeren }\end{array}$ & 2,9 & $2,0-4,2$ & 1,2 & $0,9-1,5$ \\
\hline . dagelijkse en huiselijke bezigheden & 11,1 & $6,3-19,4$ & 1,3 & $1,0-1,6$ \\
\hline - sociale bezigheden, relaties, seksualiteit & 3,5 & $2,3-5,2$ & 1,2 & $0,9-1,5$ \\
\hline
\end{tabular}

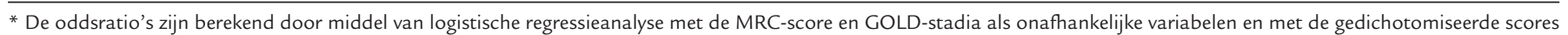
van de kwaliteit-van-levensubschalen als afzonderlijke afhankelijke variabelen 
Men mag daarom verwachten dat het onafhankelijke verband tussen dyspneuscore en kwaliteit van leven ook gevonden zal worden bij vrouwelijke rokers. Ten derde hadden $236(59,7 \%)$ deelnemers geen luchtwegobstructie. De onderzoeksresultaten zouden bij deelnemers mét luchtwegobstructie anders kunnen zijn dan bij deelnemers zónder luchtwegobstructie. Als wij de analyse echter beperkten tot de deelnemers met luchtwegobstructie, dan vonden wij dezelfde associaties. Ten slotte was bij 41 (9\%) deelnemers de spirometrie inadequaat of waren de vragenlijsten incompleet. Deze 41 verschilden echter niet van de andere deelnemers op de in tabel 2 genoemde kenmerken.

Het verband tussen dyspneu en longfunctie enerzijds en kwaliteit van leven anderzijds is al eerder in diverse onderzoeken bestudeerd. Bij personen met matig ernstig of ernstig COPD (GOLDstadium II of hoger) was de kwaliteit van leven sterker geassocieerd met de ernst van de dyspneu dan met de ernst van de ziekte gebaseerd op de longfunctie.8,9,20,30 Voor zover ons bekend is, is er één ander onderzoek verricht onder personen met COPD in een vroeg stadium (GOLD 0-II). De onderzoekers concludeerden dat de overgang van GOLD 0 naar GOLD II niet gepaard ging met belangrijke verschillen in gezondheidstoestand. Dit komt overeen met onze resultaten. ${ }^{5}$ In andere onderzoeken was comorbiditeit gerelateerd aan vermindering van de kwaliteit van leven, onafhankelijk van de ernst van COPD. ${ }^{17,24}$

De eendimensionale gradering van de ernst van COPD, alleen

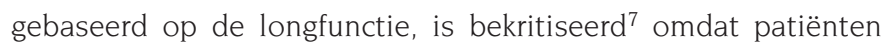
de dokter niet consulteren vanwege een lage longfunctie maar vanwege luchtwegklachten en functionele beperkingen. Uit veel onderzoeken is gebleken dat door eendimensionale gradering op basis van de $\mathrm{FEV}_{1}$ een belangrijk deel van de invloed van dyspneu en andere aspecten van de aandoening op de individuele patiënt uit het zicht verdwijnt. In de GOLD-gradering ontbreekt een index die de invloed van luchtwegklachten op het lichamelijk functioneren meet, zoals de NYHA-classificatie doet bij patiënten met hartfalen. Sommige auteurs hebben daarom voorgesteld om voor matig ernstig of ernstig COPD een multidimensionale ernstindex te hanteren die gebaseerd is op longfunctie, BMI, dyspneu en inspanningsvermogen. ${ }^{31}$

\section{Conclusie}

In de dagelijkse praktijk zou men bij individuele patiënten met een verhoogde kans op COPD of al met bekend COPD niet alleen veranderingen in de longfunctie moeten registreren maar ook, met behulp van de MRC-dyspneuschaal, veranderingen in het lichamelijk functioneren. Dit is nodig om richting te geven aan de medische behandeling en vooral aan stoppen-met-rokeninterventies. Bij rokers van middelbare leeftijd heeft de beperking van het lichamelijk functioneren door dyspneu, zoals gemeten met de MRC-dyspneuschaal, meer invloed op de kwaliteit van leven dan de ernst van de luchtwegobstructie. Toekomstige indelingen van COPD dienen hiermee rekening te houden en niet alleen uit te gaan van de $\mathrm{FEV}_{1}$.

\section{Dankbetuiging}

Met dank aan de huisartsen in IJsselstein die pro deo deelnamen aan dit onderzoek.

\section{Literatuur}

1 Pauwels RA, Buist S, Calverley PMA, Jenkins CR, Hurd SS on behalf of the GOLD Scientific Committee. Global strategy for the diagnosis, management and prevention of chronic obstructive pulmonary disease; NHLBI/WHO Global Initiative for Chronic Obstructive Lung Disease (GOLD). Am J Respir Crit Care Med 2001;163:1256-76.

2 Fabbri LM, Hurd SS, for the GOLD Scientific Committee. Global strategy for the diagnosis, management and prevention of COPD: 2003 update. Eur Resp J 2003;22:1-2.

3 Wilson IB, Cleary PD. Linking clinical variables with health related quality of life. JAMA 1995;273:59-65.

4 Wijnhoven HAH, Kriegsman DMW, Hesselink AE, Penninx BWJH, De Haan M. Determinants of different dimensions of disease severity in asthma and COPD; pulmonary function and health related quality of life. Chest 2001; 119:1034-42.

5 Antonell-Incalzi R, Imperiale C, Bellia V, et al. Do GOLD stages of COPD severity really correspond to difference in health status? Eur Respir J 2003;22:444-449.

6 Bestall JC, Garrod PR, Garnham R, Jones PW, Wedzicha JA. Usefulness of the Medical Research Council (MRC) dyspnoea scale as a measure of disability in patients with chronic obstructive pulmonary disease. Thorax 1999;54:581-6.

7 Kerstjens HAM. The GOLD classification has not advanced understanding of COPD. Am J Respir Crit Care Med 2004;170;212-3.

8 Mahler DA, Mackowiak JI. Evaluation of the Short-Form 36-Item questionnaire to measure health-related quality of life in patients with COPD. Chest 1995; 197:1585-9.

9 Hajiro T, Nishimura K, Tsukoni M, Ikeda A, Oga T, Izumi T. A comparison of the level of dyspnoea vs disease severity in indicating the health-related quality of life of patients with COPD. Chest 1999; 116:1632-7.

10 Geijer RMM, Sachs APE, Hoes AW, Salomé PL, Lammers J-WJ, Verheij TJM. Prevalence of undetected persistent airflow obstruction in male smokers 40-65 years old. Fam Pract 2005;22:485-9.

11 American Thoracic Society. Standardization of spirometry, 1994 update. Am J Respir Crit Care Med 1995;152:1107-36.

12 Quanjer PH, Tammeling GJ, Cotes JE, Pedersen OF, Peslin R, Yernault JC. Lung volumes and forced ventilatory flows. Report Working Party Standardization of Lung Function Tests, European Community for Steel and Coal. Official Statement of the European Respiratory Society. Eur Respir J Suppl 1993;16:5-40.

13 Thiadens HA. Questionnaire diagnosing asthma or COPD in patients with persistent cough: variations on a theme [dissertation]. Leiden: University of Leiden, 1999

14 Fletcher CM. Standardized questionnaire on respiratory symptoms: a statement prepared and approved by the MRC Committee on the Aetiology of Chronic Bronchitis (MRC breathlessness score). BMJ 1960;2:1665.

15 Aaronson NK, Muller M, Cohen PD, Essink-Bot ML, Fekkes M, Sanderman $\mathrm{R}$, et al. Translation, validation, and norming of the Dutch language version of the SF-36 Health Survey in community and chronic disease populations. J Clin Epidemiol 1998;51:1055-68.

16 Maille AR, Koning CJ, Zwinderman AH, Willems LN, Dijkman JH, Kaptein AA. The development of the 'Quality-of-life for Respiratory Illness Questionnaire (QOL-RIQ)': a disease-specific quality-of-life questionnaire for patients with mild to moderate chronic non-specific lung disease. Respir Med 1997;91:297-309.

17 Van Manen JG, Bindels PJE, Dekker FW, Bottema BJ, Van der Zee JS, IJzermans CJ, et al. The influence of COPD on health-related quality of life independent of the influence of co-morbidity. J Clin Epidemiol 2003;56:1177-84.

18 Curtis, JR, Patrick DL. The assessment of health status among patients with COPD. Eur Resp J 2003;21: Suppl 41:36S-45S.

19 Van Stel HF, Maillé R, Colland VT, Everaerd W. Interpretation of change and longitudinal validity of the quality of life for respiratory illness 
questionnaire (QOL-RIQ) in inpatient pulmonary rehabilitation. Qual Life Res 2003;12:133-45.

20 Hajiro T, Nishimura K, Tsukoni M, Ikeda A, Koyama H, Izumi T. Comparison of discriminative properties among disease-specific questionnaires for measuring health-related quality of life in patients with chronic obstructive pulmonary disease. Am J Respir Crit Care Med 1998; 157:785-90.

21 Viramontes JL, O'Brien B. Relationships between symptoms and health-related quality of life in chronic lung disease. J Gen Intern Med 1994;9:46-8.

22 Maillé AR. Quality of life in asthma and COPD. Development of a disease-specific questionnaire [dissertation]. Amsterdam: University of Amsterdam, 2000.

23 Hajiro T, Nishimura K, Tsukino M, Ikeda A, Koyama H, Izumi T. Analysis of clinical methods used to evaluate dyspnoea in patients with chronic obstructive pulmonary disease. Am J Respir Crit Care Med 1998; 158:1185-9

24 Ferrer M, Alonso J, Morera J, Marrades RM, Khalaf A, Aguar MC, et al. Chronic obstructive pulmonary disease stage and health-related quality of life. The Quality of Life of Chronic Obstructive Pulmonary Disease Study Group. Ann Intern Med 1997;127:1072.

25 Engström CP, Persson LO, Larsson S, Sullivan M. Health-related qua- lity of life in COPD: why both disease-specific and generic measures should be used. Eur Respir J 2001;18:69-76.

26 Langhammer A, Johnsen R, Gulsvik A, Holmen TL, Bjermer L. Sex differences in lung vulnerability to tobacco smoking. Eur Respir J 2003: 1017-23.

27 Langhammer A, Johnsen R, Holmen J, Gulsvik A, Bjermer L. Cigarette smoking gives more respiratory symptoms among women than among men. J Epidemiol Community Health 2000;54:917-22.

28 Kerstjens HA, Rijcken B, Schouten JP, Postma DS. Decline of FEV 1 by age and smoking status: facts, figures, and fallacies. Thorax. 1997;52:820-7.

29 Braspenning JCC, Schellevis, FG, Grol RPTM, redactie. Tweede Nationale Studie naar ziekten en verrichtingen in de huisartspraktijk: Kwaliteit huisartsenzorg belicht. Utrecht: NIVEL/WOK, 2004.

30 Hajiro T, Nishimura K, Tsukino M, Ikeda A, Oga T. Stages of disease severity and factors that affect the health status of patients with chronic obstructive disease. Respir Med 2000;94:841-6.

31 Celli BR, Cote CG, Marin JM, Casanova C, Montes de Oca M, Mendez RA, et al. The body-mass index, airflow obstruction, dyspnea, and exercise capacity index in chronic obstructive pulmonary disease. $\mathrm{N}$ Engl J Med 2004;350:1005-12.

\section{Antibiotica}

Antibiotica helpen zelden bij keelontsteking, bronchitis of kaakholteontsteking. Dit is de boodschap van praktijkrichtlijnen. Praktijkrichtlijnen zijn strenge regels, gebaseerd op onderzoeken die het effect van antibiotica meten. Bij luchtweginfecties, de gewone huis-, tuin- en keukeninfecties, blijkt dat het niet zoveel uitmaakt of je afwacht of een bacteriedodend middel gebruikt.

Toch schrijven we vaker antibiotica voor dan we mogen. Dat komt omdat die praktijkrichtlijnen geschreven zijn op basis van onderzoeken over gemiddelden, over de richting van wat verstandig medisch handelen is. Nergens staat de naam van een patiënt in die richtlijn. Misschien is hij wel de uitzondering op de regel. Misschien is hij wel niet gemiddeld. Stel dat zijn ervaring is dat zijn vieze keelontsteking, koortsende rochelhoest of pijnlijke holteontsteking nooit vanzelf overgaat; dat het niet uitmaakt of hij nu vier dagen of veertien dagen afwacht. Dan haalt hij voortaan een kuurtje penicilline op de vierde dag. Steeds knapt hij dan in twee dagen op. Hij, niet een ander. Want die ander is gemiddeld, hij niet.

Als deze patiënt mij van zijn uitzonderlijkheid overtuigt, krijgt hij direct een kuurtje penicilline. Maar hij moet eerst uitproberen of hij wel die uitzondering is. Hij moet bij een paar luchtweginfecties eerst bekijken of die richtlijn voor hem geldt, of het vanzelf overgaat als hij afwacht. Is dat niet zo, dan is hij uitzonderlijk, infectieus gezien dan. Tot die tijd is hij een gemiddeld mens en heeft hij mijn recepten niet nodig. Dan zie ik alleen de uitzonderingen. Dan volgt híj de praktijkrichtlijn en niet ik.

Nico van Duijn 